\title{
Assessing Postoperative Benefits of a Nerve Block: Study Design is Critical [Letter]
}

\author{
Wen-Xuan Chen' \\ Fu-Shan Xue (1D ${ }^{2}$ \\ Cheng-Wen Li $\mathbb{1}^{2}$
}

'Sixth Clinical Medical College and Beijing Anzhen Hospital, Capital Medical University, Beijing, People's Republic of China; ${ }^{2}$ Department of Anesthesiology, Beijing Friendship Hospital, Capital Medical University, Beijing, People's Republic of China
Correspondence: Fu-Shan Xue Department of Anesthesiology, Beijing Friendship Hospital, Capital Medical University, No. 95 Yong-An Road, Xi-Cheng District, Beijing 100050 , People's Republic of China Tel +86-139|1।177655

Fax +86-10-63138362

Email xuefushan@aliyun.com;

fushanxue@outlook.com

\section{Dear editor}

By a prospective, randomized, double-blind, placebo-controlled trial including 68 female patients with elective unilateral modified radical mastectomy, Rao et $\mathrm{al}^{1}$ assessed the effect of preoperative ultrasound-guided thoracic paravertebral block (TPVB) on postoperative quality of recovery and showed that TPVB enhanced the quality of recovery and improve postoperative analgesia. Although the valuable study has been actualized, there are several issues in the design and results of this study that deserve further discussion and clarification.

First, two groups used a standard multimodal postoperative analgesic regimen including regular intravenous parecoxib $40 \mathrm{mg}$ every $12 \mathrm{~h}$ and patient-controlled intravenous analgesia (PCIA) with morphine. Furthermore, intravenous morphine 2 $\mathrm{mg}$ was given for rescue analgesia by the PCIA device, when pain visual analog scale (VAS) score was more than $3 \mathrm{~cm}$ or the patient required. Then, the quality of recovery was measured by the global QoR-40 scores at $24 \mathrm{~h}$ following surgery. However, we noted that postoperative pain VAS scores at rest and on movement within $12 \mathrm{~h}$ following surgery and AUCs of postoperative pain VAS scores over 24 $\mathrm{h}$ after surgery were significantly decreased in the TPVB group compared with the control group, indicating that control patients experienced more serious postoperative pain, especially in active state. The postoperative pain is not only a main item of the global QoR-40 scores, but also can significantly worsen the scoring of other items of the global QoR-40 scores, such as physical comfort, emotional status and physical independence after surgery. ${ }^{2}$ Thus, we consider that the difference in the postoperative quality of recovery between groups in this study is mainly due to an inferior postoperative analgesia of control patients. The available evidence indicates that nerve blocks do not provide additional benefits on the quality of recovery, when the same adequate postoperative analgesia is achieved by a multimodal analgesic regimen in the control patients undergoing breast surgery. ${ }^{3,4}$ Thus, we suggest that the primary endpoint should be measured with a comparable pain control to avoid potential bias if the study is designed to assess the benefits of a nerve block on postoperative recovery or outcomes.

Second, median of intravenous milligram morphine consumption in the first postoperative $24 \mathrm{~h}$ was significantly decreased in the TPVB group. However, the readers were not provided absolute decrease in 24-h intravenous milligram morphine consumption in the TPVB group compared with the control group, as performed in a previous study. ${ }^{5}$ Thus, it was unclear whether absolute decrease in 
24-h intravenous milligram morphine consumption in the TPVB group exceeded the recommended minimal clinically important difference in the literature, ie, an absolute reduction of $10 \mathrm{mg}$ intravenous morphine. ${ }^{6}$

Finally, this study showed that the TPVB was associated with decreased intraoperative and postoperative opioid consumptions, improved quality of recovery and postoperative analgesia, lowered incidence of postoperative nausea and vomiting, shortened length of PACU stay and enhanced patient satisfaction. These are ideal for the successful use of enhanced recovery after surgery protocols. However, this study did not observe the main quality outcomes of enhanced recovery after surgery protocols, such as the time to first ambulation, length of hospital stay, rates of transfer to acute care hospital, readmission, and others. ${ }^{7}$ Because of this limitation, an important issue that this study cannot answer is whether improved postoperative quality of recovery provided by the TPVB can be really translated into the clinical benefits of patient outcomes.

\section{Disclosure}

The authors report no conflicts of interest in this communication.

\section{References}

1. Rao F, Wang Z, Chen X, Liu L, Qian B, Guo Y. Ultrasound-guided thoracic paravertebral block enhances the quality of recovery after modified radical mastectomy: a randomized controlled trial. $J$ Pain Res. 2021;14:2563-2570. doi:10.2147/JPR.S325627

2. Myles PS, Weitkamp B, Jones K, Melick J, Hensen S. Validity and reliability of a postoperative quality of recovery score: the QoR- $40 . \mathrm{Br}$ $J$ Anaesth. 2000;84:11-15. doi:10.1093/oxfordjournals.bja.a013366

3. Abdallah FW, Patel V, Madjdpour C, Cil T, Brull R. Quality of recovery scores in deep serratus anterior plane block vs. sham block in ambulatory breast cancer surgery: a randomised controlled trial. Anaesthesia. 2021;76:1190-1197. doi:10.1111/anae.15373

4. Lanier ST, Lewis KC, Kendall MC, et al. Intraoperative nerve blocks fail to improve quality of recovery after tissue expander breast reconstruction: a prospective, double-blinded, randomized, placebo-controlled clinical trial. Plast Reconstr Surg. 2018;141:590-597. doi:10.1097/PRS.0000000000004104

5. Aarab Y, Ramin S, Odonnat T, et al. Pectoral nerve blocks for breast augmentation surgery: a randomized, double-blind, dual-centered controlled trial. Anesthesiology. 2021;135:442-453. doi:10.1097/ ALN.0000000000003855

6. Laigaard J, Pedersen C, Rønsbo TN, Mathiesen O, Karlsen APH. Minimal clinically important differences in randomised clinical trials on pain management after total hip and knee arthroplasty: a systematic review. $B r \quad J$ Anaesth. 2021;126:1029-1037. doi:10.1016/j. bja.2021.01.021

7. Afonso AM, McCormick PJ, Assel MJ, et al. Enhanced recovery programs in an ambulatory surgical oncology center. Anesth Analg. 2021;133:1391-1401. doi:10.1213/ANE.0000000000005356

Dove Medical Press encourages responsible, free and frank academic debate. The content of the Journal of Pain Research 'letters to the editor' section does not necessarily represent the views of Dove Medical Press, its officers, agents, employees, related entities or the Journal of Pain Research editors. While all reasonable steps have been taken to confirm the content of each letter, Dove Medical Press accepts no liability in respect of the content of any letter, nor is it responsible for the content and accuracy of any letter to the editor.

Journal of Pain Research

\section{Dovepress}

\section{Publish your work in this journal}

The Journal of Pain Research is an international, peer reviewed, open access, online journal that welcomes laboratory and clinical findings in the fields of pain research and the prevention and management of pain. Original research, reviews, symposium reports, hypothesis formation and commentaries are all considered for publication. The manuscript management system is completely online and includes a very quick and fair peer-review system, which is all easy to use. Visit http:// www.dovepress.com/testimonials.php to read real quotes from published authors. 